\title{
What can student-generated animations tell us about students' conceptions of evolution?
}

Daniel Orraryd ${ }^{1 *}$ (1) and Lena A. E. Tibell ${ }^{2}$

\begin{abstract}
Background: A large body of research has investigated students' conceptions of evolutionary changes and emphasizes that students have alternative conceptions about their causes. A conventional way to monitor students' conceptions is through inventories where researchers analyse their written answers. However, textbooks are being increasingly complemented with, or even replaced by, various multimedia materials where multiple modes are used to communicate evolutionary processes. This has profound implications for students'learning, and highlights that allowing different modes of expression may influence which knowledge they present. Therefore, the goal of this exploratory study is to expand the understanding of students' conceptions of evolution through natural selection by applying student-generated stop-motion animations to reveal their conceptions. Forty-seven Swedish upper secondary school students generated 18 animations concerning evolution through natural selection. We analysed these animations qualitatively using content analysis to reveal key concepts, alternative conceptions and connections between organizational levels and time. This analysis is related to findings from previous studies on students' conceptions of evolutionary change.

Results: Our study highlights some of the benefits and limitations of using these two assessment methods. In terms of identifying alternative conceptions, a clear difference between the results of the two methods of assessment was observed. In particular, the alternative conception of essentialism appeared to a lesser extent in the student's animations than in their written responses, while natural selection as an event was more prevalent.

Conclusions: These findings support the view that students' expression of different misconceptions is influenced by the context and representational form. The work also reveals that generating stop-motion animations to explain scientific concepts is an engaging approach that stimulates students to explore their understanding in a creative and personal manner. This is potentially positive for engagement and learning. The potential for complementing standard paper-and-pen tests with tasks that encompass stop-motion animations is also discussed.
\end{abstract}

Keywords: Student-generated animation, Natural selection, Stop-motion animations, Alternative conceptions

\section{Introduction}

Knowledge about students' conceptions of a topic is essential not only for teachers' ability to orchestrate effective and appropriate learning interventions, but also to

\footnotetext{
*Correspondence: daniel.orraryd@liu.se

1 Department of Behavioural Sciences and Learning, Technology

and Science Education Research, Linköping University, Norrköping, Sweden

Full list of author information is available at the end of the article
}

assess students' progress (Smith and Tanner 2010). The most common way to test conceptual understanding is through written tests, often using specific test packages (Anderson et al. 2002; Nehm et al. 2012). However, textbooks are increasingly being complemented with, or even replaced by, a variety of multimedia materials (Lowe et al. 2017), and scientists are progressively using multiple modes to develop and communicate theories (Ainsworth et al. 2011; Treagust and Tsui 2013). This has profound implications for assessing students' knowledge, because

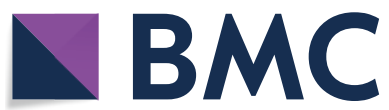

(c) The Author(s) 2021. Open Access This article is licensed under a Creative Commons Attribution 4.0 International License, which permits use, sharing, adaptation, distribution and reproduction in any medium or format, as long as you give appropriate credit to the original author(s) and the source, provide a link to the Creative Commons licence, and indicate if changes were made. The images or other third party material in this article are included in the article's Creative Commons licence, unless indicated otherwise in a credit line to the material. If material is not included in the article's Creative Commons licence and your intended use is not permitted by statutory regulation or exceeds the permitted use, you will need to obtain permission directly from the copyright holder. To view a copy of this licence, visit http://creativecommons.org/licenses/by/4.0/. The Creative Commons Public Domain Dedication waiver (http://creativeco mmons.org/publicdomain/zero/1.0/) applies to the data made available in this article, unless otherwise stated in a credit line to the data. 
the test format influences the knowledge that they present (Nehm and Ha 2011). Thus, a detailed investigation of the impact of incorporating multimedia representations on students' learning and assessment of their knowledge is needed (Lowe et al. 2017; Nielsen et al. 2020; Rector et al. 2013).

To address this need, we have explored the signs of students' knowledge of evolution via natural selection provided by the creation of multimedia, stop-motion animations, in relation to a common written test. Here, we describe how students represented how organisms can undergo evolutionary change in a collaborative animation generation task. We analyse how they expressed five key concepts, three alternative concepts, and evolutionary time, and how they made connections between organizational levels.

\section{Background}

One way to structure, teach and probe students' knowledge about the theory of evolution through natural selection (ENS), is to divide the content into key concepts (Bishop and Anderson 1990; Mayr 1982; Nehm and Reilly 2007; Tibell and Harms 2017). However, different researchers use different combinations of key concepts. For example Bishop and Anderson (1990) studied students' understanding of ENS based on three key concepts, Nehm and Reilly (2007) recognized seven, while Tibell and Harms (2017) use nine in connection with three main principles. The following paragraph outlines both the understanding of natural selection and five of the previously used key concepts (italicized) adopted here. In addition, we have specifically focused on the connection between different organizational levels and how students express time and generations.

Genetic changes such as random mutations and genetic recombination within organisms' genomes, serve as the origin of variation. It is important to understand that genes and other genetic material (genotypes) lead to individual variation, through interactions with environmental factors, which are constituted as variations in individual phenotypes (morphology, structure, behaviour and other characteristics). Offspring inherit their complement of genetic materials from their parents and thus, will also share most of their phenotypic traits. Numerous factors influence an organisms' survival, such as the availability of nutrients or energy and the presence of predators. Organisms within a specific environment with traits that confer advantages over their competitors, will have higher probabilities of surviving to reproductive maturity. This results in differential survival, and genes carried by successful individuals are likely to become more frequent in successive generations. Hence, populations evolve in particular directions (Mayr 1982), resulting in population change over time. Thus, an additional factor to consider when reasoning about natural selection is time-a new trait will not become dominant in the population until many generations have passed. As emphasized in the following definition of evolution in the Henderson dictionary of biology: ".... the development of new types of living organisms from pre-existing types by the accumulation of genetic differences over long periods of time." (Lawrence 2005, p. 218) Therefore, learners must develop the ability to connect events such as mutations with nanosecond timeframes to individual life spans, and much longer processes spanning multiple generations, and even deep geological time (Tibell and Harms 2017). It should be recognized that this is a gross simplification because sudden events such as an asteroid impact or flood may cause very rapid changes in a populations' gene frequencies.

In summary, ENS can be said to encompass five key yet simplified concepts, which are used as reference points for the scientific perspective employed in this study. However, these concepts will not make much sense to learners unless they are given meaning by applying them to comprehensible examples such as the evolution of fast-moving predators like cheetahs, or succulent plants with water storing leaves. The concepts are given meaning in explanations such as of how species evolved from common ancestors into the diverse lifeforms that we can observe today. Thus, it is important to present scientific explanations in a manner that is comprehensible for students.

\section{Alternative conceptions}

The advent of the theory of natural selection enabled explanations for the diversity of living organisms without erroneously introducing some kind of guiding force or inherent goal in evolution (Mayr 1982). However, students at all educational levels tend to use pre-Darwinian reasoning to explain evolutionary change (Harms and Reiss 2019; Mayr 1982; Nehm and Schonfeld 2008) which is characterized by: explanations based on ideas such as intentionality, or essentialism (Coley and Tanner 2015; Ware and Gelman 2014), and descriptions of major evolutionary changes expressed in event like ways (Harms and Reiss 2019). The literature reports on a multitude of alternative conceptions that students display when attempting to explain evolution. In this study, these alternative conceptions are grouped into the three categories described above.

One major difficulty in conceptualising evolutionary change seems to be accepting that evolution is a natural process without any goal or directing force. In this paper such conceptions are compiled into the category termed intentionalism. For example, explaining a change based on its outcome or purpose is often referred 
to as a teleological approach. This leads to the alternative conception that variation occurs through direct response to needs evoked by the environment (Southerland et al. 2001). Alternatively, the idea that traits which are acquired (based on purpose or intentional use) by an individual during its lifetime are passed on to any offspring. Anthropomorphic reasoning ascribes human attributes to organisms, such as the ability to plan for the lives of future generations (Coley and Tanner 2015) (together with an implied super-human ability to modify their characteristics accordingly). In many cases, the intention behind the change originates in nature itself, which act as an agent for giving a direction to the changes (Gregory 2009).

Research has also shown that many learners perceive the individuals of a species as sharing a common essence or type, and disregard variations between individuals as inconsequential (Gelman and Rhodes 2012). Applied to evolutionary change, this conception may lead to the idea that such change is a process of altering the common essence shared by all individuals of the species. When the essence is changed, all members of the species change with it. This is in conflict with the scientific view of evolutionary change as a change in the distribution of a trait within a population (Gregory 2009). This alternative conception of thinking that species are unified by some sort of metaphysical essence is referred to as essentialism.

Moreover, research has shown that students have difficulties with both short and extensive timescales in natural selection (Ferrari and Chi 1998). Students therefore often fail to perceive evolutionary changes as a continuous process of genetic change that involves extremely rapid alterations (e.g., mutations), and responses to selective pressures that act over enormously varying timescales, including gradual change over thousands of generations. Students also tend to conceptualize natural selection as proceeding via intermittent events (Harms and Reiss 2019), in which species adapt by solving specific problems and then remain more or less the same until another problem arises. For convenience, this is referred to as the alternative conception of natural selection as an event, or simply event.

In summary, students have to perceive both different levels of organization and varying time scales in order to be able to move from a goal-directed, intentional, form of reasoning. This include to see that natural selection requires variation within the population that occurs by means of random events, is present before any selection can occur and that the variation is not a consequence of environmental pressure (Tibell and Harms 2017). In this case we chose to use the three main categories of intentions, essentialism, and event because these were the main alternative conceptions that we were able to observe in the animations. To monitor students advancements in the form of their reasoning about evolution, we need valid methods for probing students' conceptions.

\section{The nature of alternative conceptions}

The method applied for investigating students' conceptions is influenced by assumptions regarding how people form and link ideas. Some researchers view students' knowledge as coherent intutive conceptual frameworks (Coley and Tanner 2015) while others view it as a more fluid collection of smaller phenomenological primitives (diSessa 1993). This is an ongoing area of research with relevance to the field of evolution education. Recently, the debate has been revisited by Gouvea and Simon (2018), who problematized the multiple choise instrument used by another team of researchers (Coley and Tanner 2015). Their criticism was that, by using ambiguously formulated questions and alternatives Coley and Tanner (2015) were 'tricking' students into choosing the options that represented the alternative conception, thus failing to capture students' real conceptions. When the formulations were changed to state more directly what was really meant, Gouvea and Simon (2018) found that students performed better than with the original test items used by Coley and coworkers. Gouvea and Simon (2018) claim that their results are difficult to explain using the notion of "intuitive ways of knowing" that Coley and Tanner (2015, p. 1) termed cognitive construals.

Studying the nature of students conceptions can also be achieved by analysing the consistency of their use in diffeernt contexts, where students need to transfer their understanding (Pugh et al. 2014) from one context to another (Göransson et al. 2020), or switch medium, for example, from written to drawn or animated forms (Kampourakis 2007). Changing the social context, e.g., individual to colaborative may also be significant (Pugh et al. 2014). More research is clearly needed to resolve this issue. We contribute with a study of student-generated animations, created in a colaborative setting.

\section{Visual representations of natural selection}

Visual representations are indispensable in biology education (Treagust and Tsui 2013). However, typical visual representations of evolution such as cladograms and phylogenetic trees can be difficult to interpret (Catley et al. 2010). For example, a cladogram or phylogenetic tree is constructed to represent the history of how the unity and diversity of living organisms arose, not the mechanisms responsible for changes in species (Matuk and Uttal 2012). Consequently several misunderstandings related to the interpretation of the temporal aspects of evolutionary trees have been reported (Gregory 2008), and such representations do not seem to facilitate an explicit 
understanding of the temporal aspects of evolution (Stenlund and Tibell 2019).

The public image of evolution is strongly influenced by historical pre-Darwinian representations (Archibald 2014). For example, in a study by Matuk and Uttal (2012) where undergraduate students were asked to draw an image of evolution $42 \%$ generated some variant of the iconic "March toward Man" image. The perception that life evolves along a ladder, in a linear manner, referred to as the great chain of being (Abrams and Southerland 2001), is common. That is not to say that there are no representations of the mechanisms involved; for instance, there is a plethora of animations and simulations available as educational resources on the internet. These are very diverse and not bound by disciplinary rules, as shown in a study by Bohlin et al. (2017). Yet, using student-generated animations to provide new insights into student conceptions remains unexplored.

\section{Assessment-from text only to multimedia}

In biology education, there has been a proliferation of explanatory animations to support student's learning (Lowe et al. 2017; Phillips et al. 2010). Textbooks are being replaced with new multimedia displays that have increasing degrees of interactivity. However, this shift from text to animation in teaching is not mirrored in accompanying assessment methods (Nielsen et al. 2020).

Student conceptions of evolution and natural selection have been probed using interviews, and various paper-and-pencil tests, ranging from multiple choice to essays (e.g. Anderson et al. 2002; Bishop and Anderson 1990; Nieswandt and Bellomo 2009). A comparison has shown that each method of assessment may reveal different aspects of the same subjects' conceptions (Nehm and Schonfeld 2008). The context of test items may also influence the levels of understanding and patterns of alternative conceptions displayed (Göransson et al. 2020; Nehm et al. 2012). Moreover, most of these tests are lexical, thereby preventing students from using other media, such as pictorial resources, to represent their understanding.

This emphasis on a single test format might be problematic. If a student is expected to write about what s/ he might have learnt from watching an animation or simulation, there is a risk that the translation between modes may interfere with the intended outcome (Lowe et al. 2017). Assuming that each representational mode has strengths and weaknesses that constrain what can be expressed (Prain and Tytler 2012), the assessment may not provide a valid representation of students' conceptions. Lowe et al. (2017) also report that written explanations are often insufficient representations of the knowledge learners have acquired from studying an animation.

It may be important to distinguish between two types of representations: descriptive (e.g. writing) and depictive (e.g. animations) (Schnotz 2002). The first is by necessity symbolic because, for example, the letters in a word bear no resemblance to the object they represent, whereas the second type can be more analogous to and often depict, the referents. Due to such differences, some aspects of a topic may be easily represented in one mode but troublesome in another. For instance, a depictive representation has the potential to convey simultaneous events directly while the linear format of a descriptive representation constrains that possibility (Prain and Tytler 2012).

Following the reasoning above, an exploration of what student-generated dynamic representations can reveal about students' conceptions would be valuable. If students learn by watching animations and are then required to explain using only lexical representations, this requires translation from one medium to another. Using animations as the medium of assessment avoids this transfer challenge. Akaygun (2016) claims that student-generated animations can be powerful assessment tools, particularly to reveal conceptions of a dynamic character. Detailed explorations of such claims are clearly warranted together with in depth analyses of the usability of student-generated multimedia animations to probe students' conceptions (Lowe et al. 2017; Mintzes et al. 2001; Rector et al. 2013).

\section{Stop motion animations in biology education}

Stop-motion is an open format and intuitive technique for generating animations (Hoban and Nielsen 2010) that can support students' conceptual development (Farrokhnia et al. 2020). Stop-motion is a technique in which one physically moves objects and photographs them one frame at a time. Subsequently displaying the photos in a sequence creates the illusion of movement. It is also possible to add narration, music, or additional visual or auditory effects during the final editing phase. In order to re-represent a phenomenon in a series of different modes, the learner is required to re-evaluate and develop his or hers ideas (Berg et al. 2019; Hoban and Nielsen 2010). Using visual media to illustrate variation allows a lot of information to be displayed simultaneously, and is potentially useful in a context involving complex processes, such as ENS. In addition, the dynamic medium of animation enables the representation of processes of change (Mills et al. 2019).

A study on preservice student teachers' views of using stop-motion activities in biology teaching (Karakoyun and Yapici 2018) concluded that students thought it to be a good approach for developing cooperation, 
communication and creativity. Nevertheless, they thought it was difficult to invent scenarios in which to implement the technique. Several studies have also found that generating stop-motion animations has the potential to help students achieve stipulated learning objectives regarding around cellular processes, and molecular biology (Deaton et al. 2013; Kamp and Deaton 2013; Peterson and Ngo 2015). The main finding from these studies is that students seemed to enjoy this creative way of working. A common feature in the research above is that the content concerned a microscopic scale and relatively limited time scales. Some studies have considered the utility of student-generated stop-motion animations for learning content associated with larger scales of space and time (e.g. Mills et al. 2019). However, there is a lack of studies on the possible value of using student generated animations as diagnostic tools for revealing students' conceptions.

\section{Aim}

This exploratory study concerns how students handle the task of explaining evolution through natural selection by collaboratively generating a stop-motion animation. The three main aims are to investigate:

1. What means of expression do students use when they are asked to express their knowledge in studentgenerated stop-motion animations?

2. What concepts are students able to represent in stopmotion animations?

3. How do the conceptions expressed in stop-motion animations relate to written explanations of evolutionary change in our study and previously reported research literature?

By pursuing these aims, this work provides a starting point for the development of a teaching sequence for teaching evolution through natural selection, including student collaborator created stop-motion animations.

\section{Methods}

\section{Study participants}

The subjects of this study were students (aged 16-17 years) from two classes (a total of 58 students), enrolled in the national science program in Swedish upper secondary school (Swedish gymnasium). The teachers of these classes were willing to include this task as compulsory in the evolution segment of the basic biology course but participation in the study was voluntary. All the students agreed to include their animation in the study but only 47 contributed with written explanations. The task of generating a multimedia animation was introduced at the beginning of the history of life and evolution section in the biology 1 course as an introductory assignment. Each student had previously completed the compulsory school curriculum including an introduction to the history of life.

\section{Design of the study}

Initially, a 15-min introduction to the stop-motion technique was given by experienced media educators. They also provided some of the equipment needed for generating the multimedia animations and assisted in solving technical problems during the animation workshops.

The students were divided into smaller groups of two to five and asked to generate stop-motion animations, with the following instruction:

"Organisms can undergo evolutionary change. Generate an animation that shows how this process works."

It was up to the students to choose the organisms, materials, storyline, and context for their explanation. The intended audience was peers in a parallel class who had not taken the biology course.

The groups were given three hours to generate their animations, via the following steps:

1. Creation of a short visual manuscript "storyboard".

2. Building models and a set or "stage".

3. Capturing a series of digital photos of the models and moving them a small amount between each photo.

4. Finally, editing the animation, adding narration, sound, and/or other effects (Fig. 1).

The students were also asked to individually respond to the following written question, obtained from the ORI inventory of natural selection (Andrews et al. 2011; Göransson et al. 2020; Nehm and Reilly 2007).

"Cheetahs (large African cats) are able to run faster than $100 \mathrm{~km} / \mathrm{h}$ chasing prey. How would a biologist explain how the ability to run fast evolved in cheetahs, assuming their ancestors could only run at $30 \mathrm{~km} / \mathrm{h}$ ?"

These explanations were compared to student responses in the research literature (Göransson et al. 2020; Nehm and Reilly 2007). The two tasks above requested the students to explain essentially the same process but illustrated in two different representational modalities. The time needed to do this was also different, with the stop-motion animation taking three hours and the written item about $10-15 \mathrm{~min}$ to complete, respectively. In addition, the written response was requested 


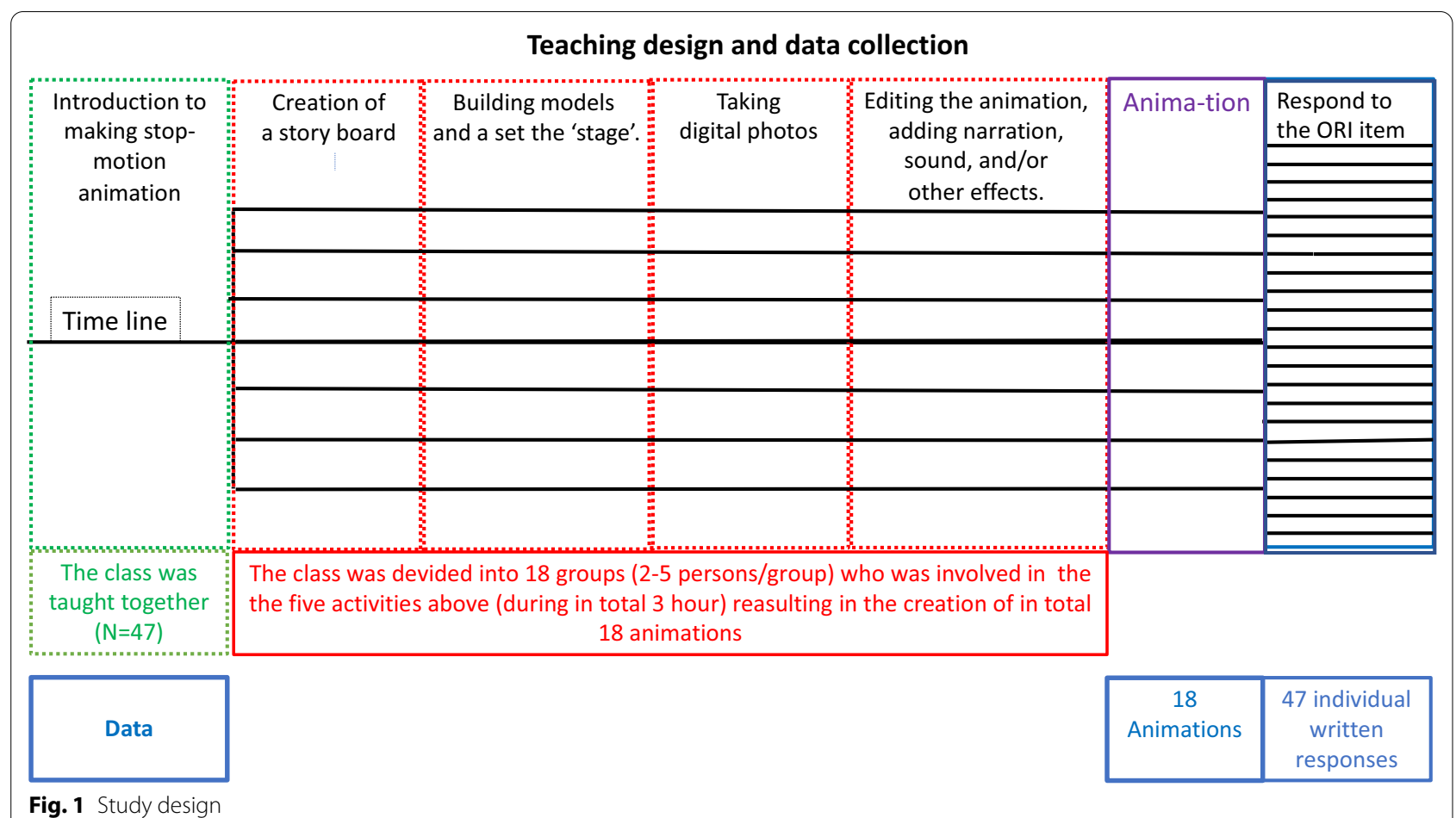

after the stop-motion animation episode was completed. An overview of the study design can be found in Fig. 1.

\section{Stop-motion animation}

The students used a digital camera connected to a desktop computer with stop-motion software (iStopmotion) to record the movies. The models were mainly made of clay, but there were also drawings, cut-outs, and other materials at hand, and placed in a set or scene (Hoban and Nielsen 2010). The movies were then exported to movie editing software (iMovie) and sound and sometimes other effects were edited into the final animation.

\section{Analysis}

Each animation was briefly described, followed by their salient, visual attributes including text and other signs subjected to inductive categorization and deductive content analysis. The inductive analysis pursued the natural discovery of themes, both concerning categories and the multimodal expressions of the disciplinary content. Emergence of a category could be expressed in one animation (Amundsen et al. 2008), while multiple categories could also relate to a single animation. Each author initially perused the same 18 multimedia animations, followed by collectively discussing any emerging category related to natural selection. In a few cases of the 180 rulings (18 animations, ten categories) there where disagreement that were discussed before the authors reached full agreement.

Concerning the design features of the stop-motion animations the following themes emerged: what sort of organism the students were choosing, how variation in characteristics were illustrated, and how selection pressure was expressed. Furthermore, reinforcing additions such as illustrative sounds, music, oral narration, or written text were registered.

The deductive analysis (Mayring 2002), was based on previous research on students' understanding and developed from a compressed version of a criteria catalogue developed by Tibell and Harms (2017) and Bohlin et al. (2017). The categories included five key-concepts (E1-E5), connections between organizational levels (T1), explicit compression or expansion of time (T2), and three alternative conceptions (A1-A3) (Harms and Reiss 2019; Nehm and Reilly 2007) (Table 1 and Additional file 1: Appendix S1).

The unit of analysis was defined as a multimedia animation. Each representation was considered in its totality for any occurrence of the categories described below (Table 1 and Additional file 1: Appendix S1). Allowing qualitative description of whether and how students included the underlying key concepts and alternative conceptions in their representations. Several categories could be assigned to the same unit of analysis. 
Table 1 List of key-concepts of evolution and alternative concepts including criteria for analysis

\begin{tabular}{ll}
\hline E1-Variation between individuals & Any differences in phenotypes-phenotypic variation. Indications of variation present \\
E2-Origin of variation & Variation arises at a genetic level. Coupling between mutations and the variation of traits is necessary \\
E3-Inheritance (including reproduction) & Offspring inherit traits from parents and pass them on to successive generations \\
E4-Differential survival & $\begin{array}{c}\text { Not all individuals in a generation survive to reproduce for reasons such as limitations in resources or } \\
\text { predator attacks } \\
\text { Favourable traits become more frequent in populations over generations }\end{array}$ \\
E5-Change in population & $\begin{array}{c}\text { Directed evolution where a new trait appears after a change in the environment. Indication that changes } \\
\text { occur because of an ultimate goal or by human-like intentions and ability to plan for a distant future }\end{array}$ \\
A1-Intentionality & Transformation of all individuals within a population. Unifying essence instead of variation \\
A2-Essentialism & Major evolutionary changes occur in less than three generations \\
A3-Natural selection as an event & Connections between organizational levels, from genes to population \\
T1-Organizational levels & Illustration/manipulation of tempo. (Fast forward or slow motion) \\
T2-Time &
\end{tabular}

a We deemed that two generations are too short of a time for evolution, equivalent to an event. When both inheritance and change in populations after at least three generations were shown, we judged it as an illustration of that mating in several generations is needed for a new property to manifest

\section{Written explanations}

The 47 written responses were analysed deductively using the same criteria catalogue as described above, and focused on the meaning manifested in each written response (Graneheim and Lundman 2004).

\section{Evaluation of the intervention}

The students evaluated the session on a scale from 1-9 to describe (1) whether creating a stop-motion animations was instructional and fun (9) or irrelevant and boring (1), or (2) whether it was very demanding (9) or not at all demanding (1).

\section{Results}

Overall, the students appeared to be stimulated by creating stop-motion animations. They did not experience it as particularly demanding (3.8) and found the session to be instructional and fun (6.7). This is a striking finding since making stop-motion animations can be tedious work. The evaluations revealed several remarks stating that the activity was different from, and more fun than, their usual science classes.

\section{Which means of expression do students use when they seek to express their knowledge in student-generated stop-motion animations?}

The length of the 18 stop-motion animations ranged between 21 and $83 \mathrm{~s}$, with a mean of $45 \mathrm{~s}$.

When choosing the organisms, all the groups used animals (Table 2). Fourteen animations (78\%) communicated more or less realistic animals. Some of these were human-like or fictional animals. Only four groups (22\%) chose to communicate symbolic (yet animal-like) organisms (Table 2). Half of the animations did either not show any generational shifts at all $(6 \%)$, or only the
Table 2 Description of the stop-motion animations

\begin{tabular}{lc}
\hline & $\begin{array}{l}\text { No. of } \\
\text { animations }\end{array}$ \\
\hline Organism & 18 \\
Animal & 14 \\
Simplified model & 4 \\
Population & \\
More than three individuals & 9 \\
More than two generations & 6 \\
Trait & 18 \\
Physical property & 14 \\
Behavioural trait & 4 \\
Selection & 16 \\
External antagonist & 12 \\
Lack of accessible food & 8 \\
\hline
\end{tabular}

parental or one generation of offspring (3\%). Six of the animations (33\%) showed three or more generations (Table 2). The represented "population" on which natural selection acted upon consisted of more than three individuals in $50 \%$ of the animations. Most of the traits to be represented were distributed between a physical (14) or a behavioural property (4), and selection pressure was represented as either an external antagonist (in 12 cases) or environmental causes (such as lack of food, 8 cases, Table 2). In two of the animations, it was not possible to detect any selection taking place at all.

The students utilized the resources that had been made available to them by the media educators. All the student groups used clay as their basic material, but this was supplemented in various ways such as paper and drawings. Some groups added thread, nails, stone, or wood shavings, and in one of the animations, Lego. In addition to the visual material mentioned above, the students added other modalities. 
Some form of audio or text was added to all but one of the stop-motion animations. Of these, sound effects and music were more common than narration. Four of the stop-motion animations included written text, either directly or in speech bubbles. One animation included music, sound effects, narration, and written text (see Table 3). Using speech bubbles, dramatic sound and sometimes also speech, these multimodal expressions contributed a humour aspect to the animations. All design features of the student generated animations are summarized in Table 3.

\section{What concepts are students able to represent in stop-motion animations?}

This section describes the key-, alternative conceptions and spatial and temporal dimensions (E1-E5, A1-A3 and $\mathrm{T} 1-\mathrm{T} 2)$ as they are represented in the stop-motion animations.

Table 3 Addition to visuals in the student generated animations

\begin{tabular}{ll}
\hline & $\begin{array}{l}\text { No. of } \\
\text { animations }\end{array}$ \\
\hline Sound & 12 \\
Music & 13 \\
Sound effect & 7 \\
Oral narration & 2 \\
Nothing & \\
Text & 4 \\
Speech bubbles & 5 \\
Written text & 16 \\
Humour/fiction & 8 \\
Towards the end & 8 \\
Throughout & \\
\hline
\end{tabular}

An animation may contain more than one addition

\section{Key concepts}

We consider several individuals in each generation with different properties as individual variation (E1). The decision to make simple models allowed the group that made the organisms with different body sizes (Fig. 2, left panel) to generate a larger population than the group who made realistic giraffes with differences in necklength (Fig. 2, right panel).

Variation in the animations is shown in two different ways: (1) Most often only one individual with a different characteristic is shown, such as camouflage or the ability to jump, making it more a variation of a type (Zabel and Gropengiesser 2011), and (2) Less frequently, several individuals had different properties (Fig. 3).

The origin of variation (E2) was only shown in one of the animations (Fig. 4). This group indicated the mutation leading to variation in phenotype through narration in combination with a visible arrow to indicate the occurring mutations.

Inheritance (including reproduction) (E3) is represented in a substantial proportion of the animations (39\%: 7 out of 18). In four of the cases, it is illustrated by mating, and in three by organisms dividing (Fig. 5). Several groups added a humorous touch to their animations when indicating that animals were mating, for example by using strange noises and rustling in the shrubbery to guide the viewer's imagination. In the purple-men animation we detected indications of the mixing of traits that occurs in sexual reproduction (Fig. 4).

Differential survival (E4) is represented in various ways in the stop-motion animations. In most cases the population of a prey species is shown to vary. Diverse traits are represented in the animations, including long legs, the ability to bounce, spikes, or spots that aid in evading predation. Given that the medium is visual, the students had to think about traits that would be easy to visualize. Consequently, most variations were morphological or visual,
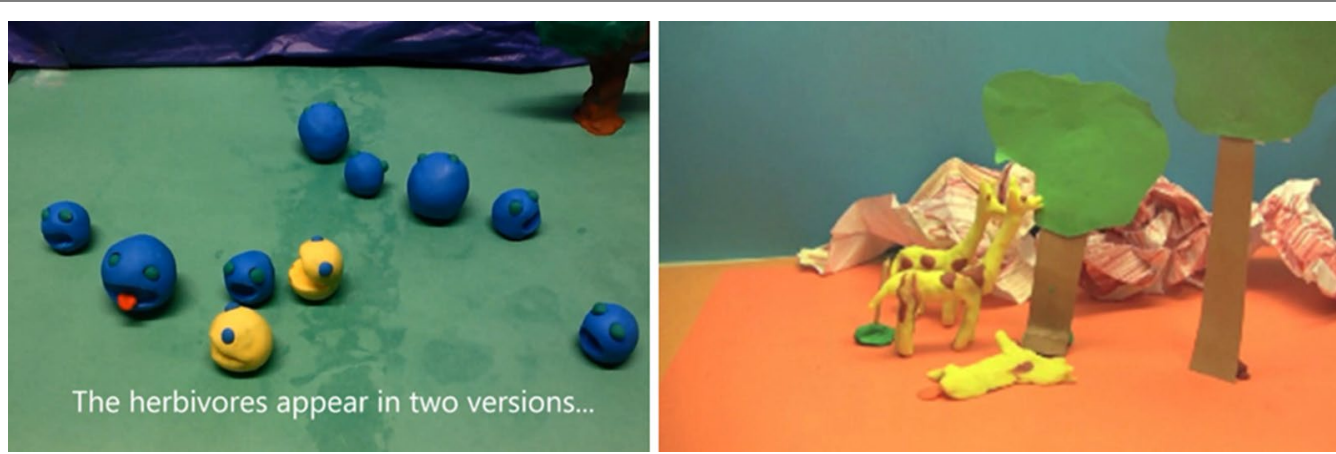

Fig. 2 Representations of populations with one varying trait, body size (left panel) and neck length (right panel), leading to the death of some variants (those with relatively small bodies and relatively short necks, respectively) 

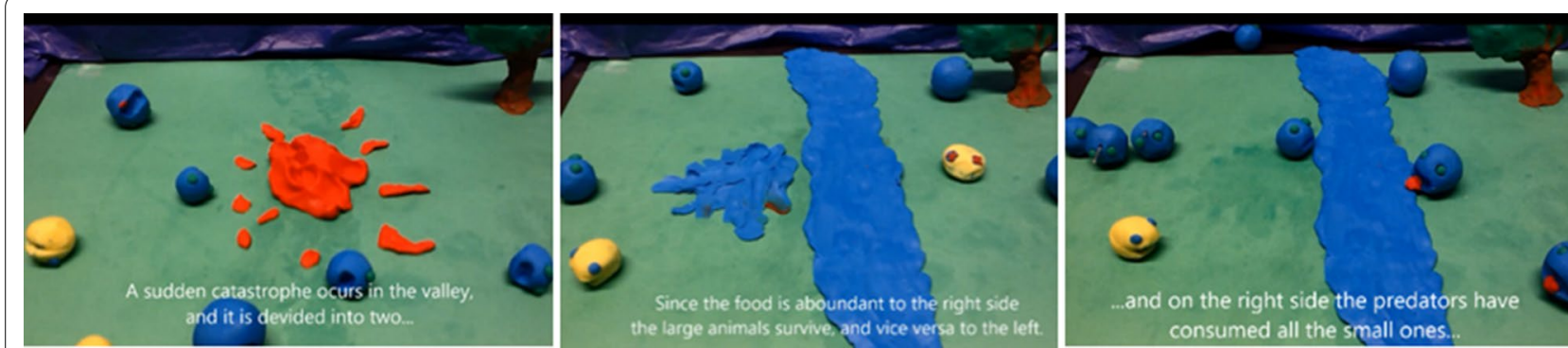

Fig. 3 Scene from one of the animations, in which a sudden change in environment lead to diverged populations, in turn leading to change in the populations
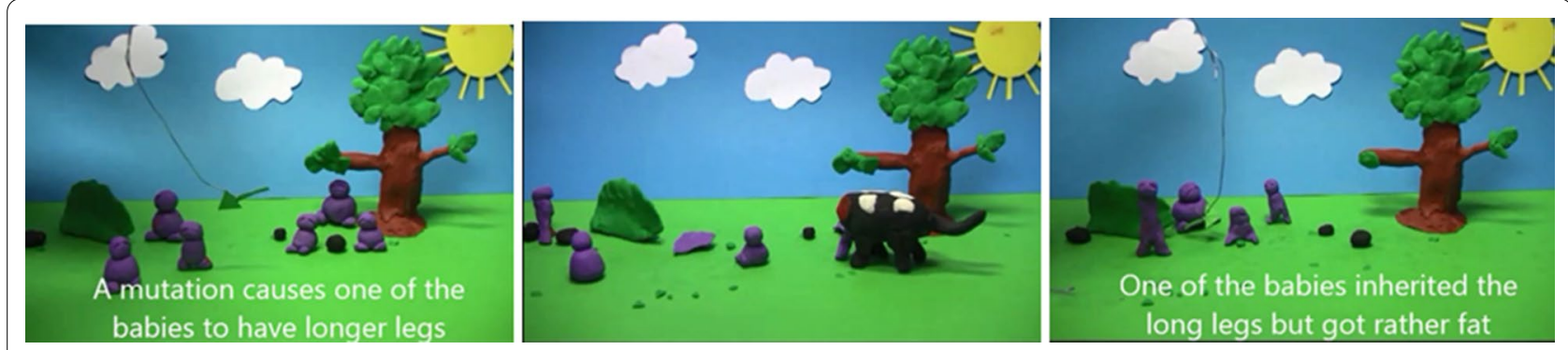

Fig. 4 Possession of legs enabling organisms to run is clearly beneficial in an environment where there are risks of being eaten. In the left panel one individual gets a mutation causing longer legs. In the illustrated animation, two offspring inherit mixtures of their parents' traits, and both acquire long legs through inheritance, but one is fat, and one is thin
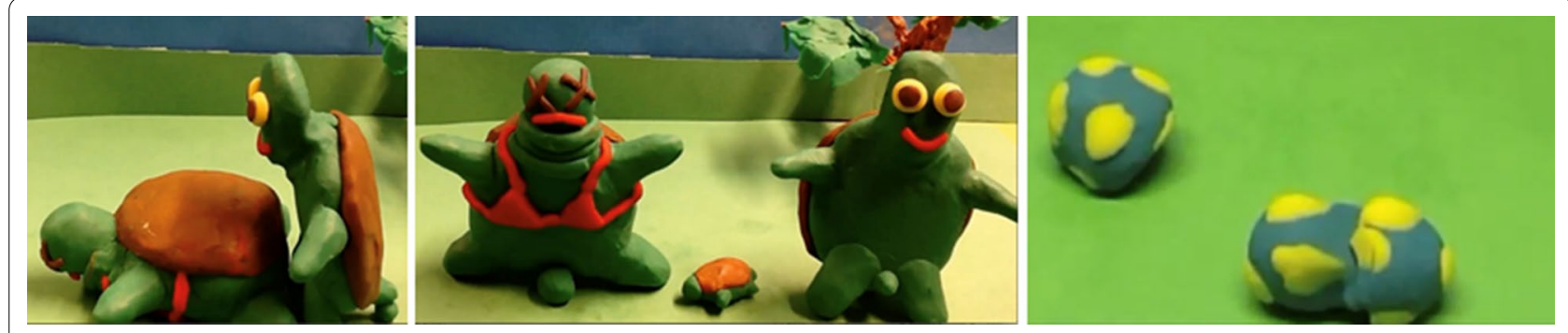

Fig. 5 Illustrations from two stop-motion animations. Inheritance is shown by the two pictures on the left (mating) and by the picture on the right (division)

such as differences in camouflage, the length of legs or necks, or body size. In a few animations the survivors had traits related to behaviour that were not expressed by other members of the population, such as greater intelligence or cooperation skills (Fig. 6).

The represented selection pressure is generally predation or lack of food (in 12 and 8 cases respectively). In one animation environmental change was shown to divide populations and introduces differences in selection pressures in the separate environments. In two cases, both predation and food limitation are illustrated (Fig. 3). In five cases a population of predators displayed variation in a trait that led them to become better hunters
(Table 2). An example of this is shown in Fig. 7 where the chameleon got a longer tongue in the succeeding generation and thereby become a better hunter.

In one case the presented storyline is more complex, with selection affecting both prey and predator populations, in a valley divided by a stream (Fig. 3). The valley is populated with symbolic animals in the form of balls of varying size. Food is plentiful on one side of the stream and scarce on the other. Food shortages causes the death of the larger prey individuals on the barren side, while on the rich side of the valley they thrive and avoid being eaten due to their size. Hence, the predators starve on the fertile side of the stream but thrive on the barren side. 


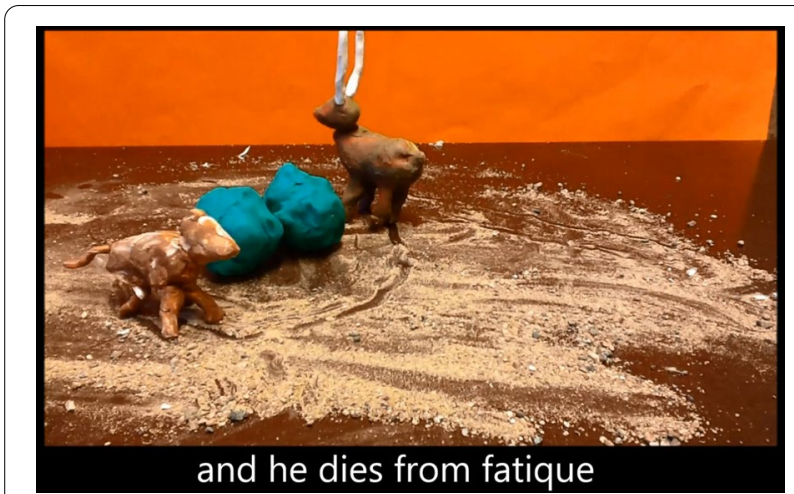

Fig. 6 Scene from one of the animations, in which the one individual who attempts to hunt on his own fail to catch the prey and therefore starve to death

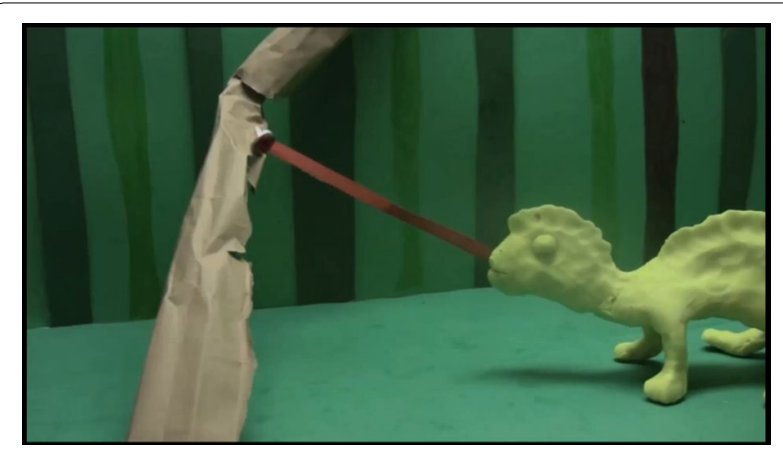

Fig. 7 Scene from one of the animations, in which the one individual who have the longest tongue is able to catch the fly while the one with a shorter tongue starves

In the student-generated stop-motion animations, the animated populations are generally very small, which makes it difficult to judge change in population (E5). In this study we consider the "initial population" as a group of more than three individuals. This is based on the results of a previous study based on video recordings of the animation process (Orraryd 2013) where the students express that the time-limitation made them compromise the population size. Using the criteria above, the concept change in population was represented in nine of the animations. Furthermore, the variation in this population is usually limited to two variants, of which one is beneficial. In other words, the random variation in the original population is missing. In addition, after selection the change in the population in most cases occurred instantaneously or after one to three generations. In other words, the accumulation of changes is not represented.

\section{Alternative conceptions}

From a science education perspective, it is easy to observe an anthropomorphic aspect, when a represented

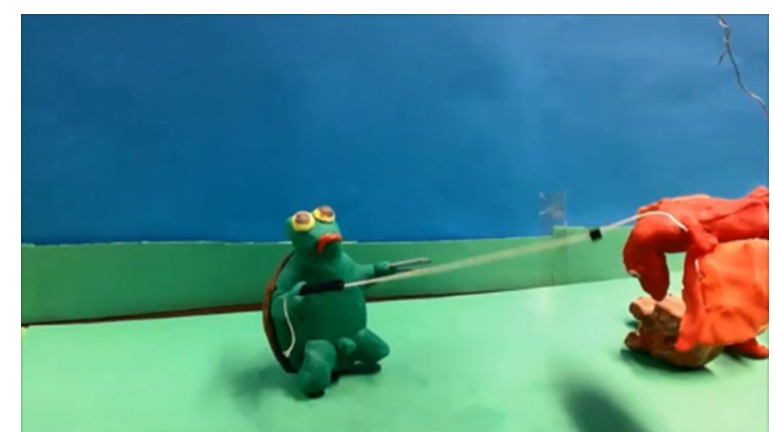

Fig. 8 Scene from one of the animations, representing one animal using a gun to defend against an attacker communicated more for a comical effect then as a scientific explanation of evolutionary change

organism appears to have human-like self-awareness. Displays of anthropomorphism include animals using weapons, living in houses, or wearing clothes (Fig. 8).

However, these displays were not categorized as intentional, and they are easier to attribute to a pure aesthetic style rather than a representation of design based on intentions (Kampourakis 2020).

Intentionality (A1) as a basis for selection was illustrated in seven animations). One animation showed a mammal adapting to life in the water by a process of metamorphosis (Fig. 9), and one used the theme of the evolution of man (Fig. 10). The students who produced these animations seemed more focused on providing a historical description of the changes in a species rather than exploring the mechanism responsible for these changes. Representing evolution as a process that is goal-directed, striving upwards or at least onwards (into the sea), is a typical expression of teleology.

A feature that these animations have in common is that they do not show any variation. One individual undergoes morphological development to be more human-like (Fig. 10) or able to swim in the sea (Fig. 9).

Previous research has pointed out that essentialism is a major alternative conception (Coley and Tanner 2015). Surprisingly, essentialism (A2) was only manifested in one animation (Fig. 2, right panel) in which the necks of all the giraffes grow (after the individual with the shortest neck has died). The necks of the remaining giraffes grew before our eyes (during their lifetime). However, the dolphin (Fig. 9) and the march towards man (Fig. 10) examples above, might be interpreted as depicting an essentialist evolution if the individual is assumed to represent the evolving essence of a population. This is not in line with our definition, so they were not included in this category.

Furthermore, evidence of the alternative conception natural selection as an event (A3) was detected in 14 of 

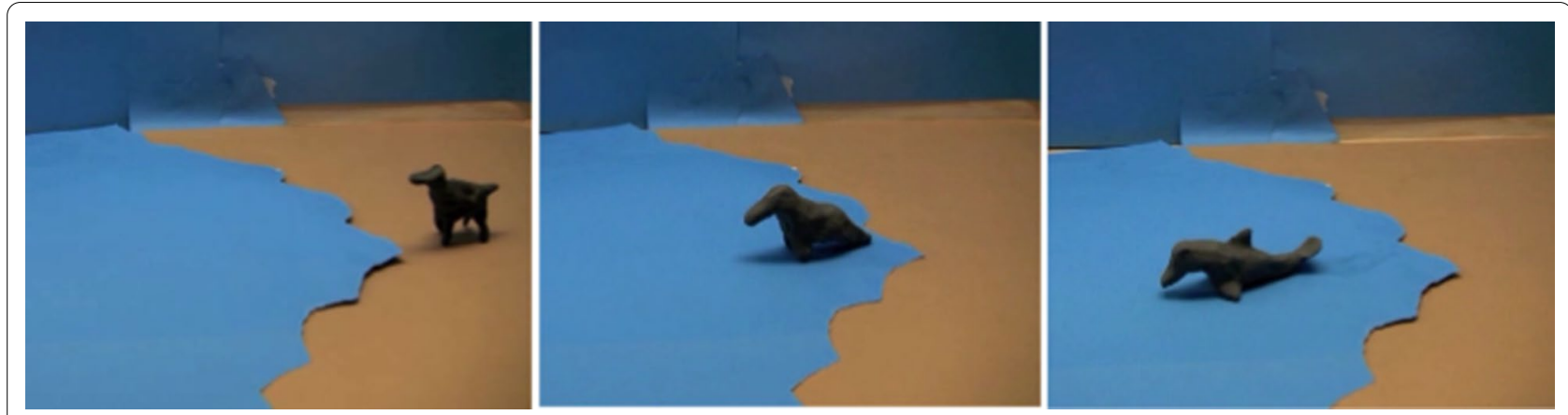

Fig. 9 Scene from one of the animations, representing one individual arriving at the beach, transforming into a dolphin as it enters the water
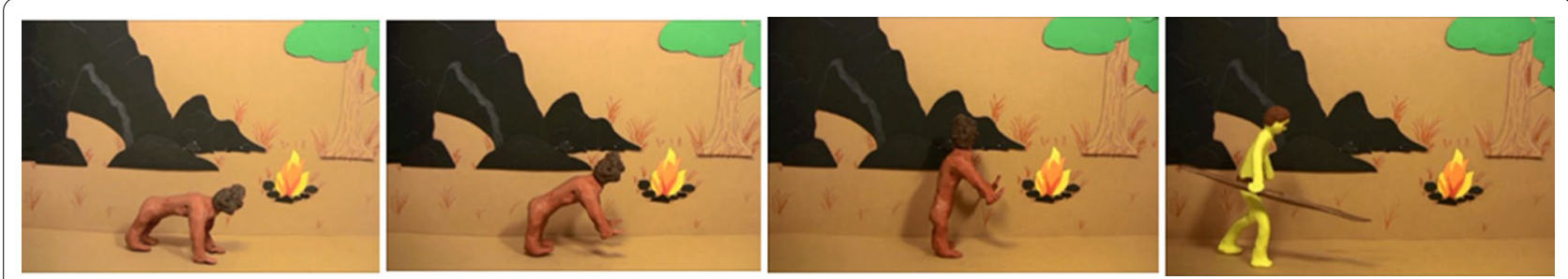

Fig. 10 Classic representation of one individual going through some sort of metamorphosis, arguably to represent the evolution of a species, was present in two animations
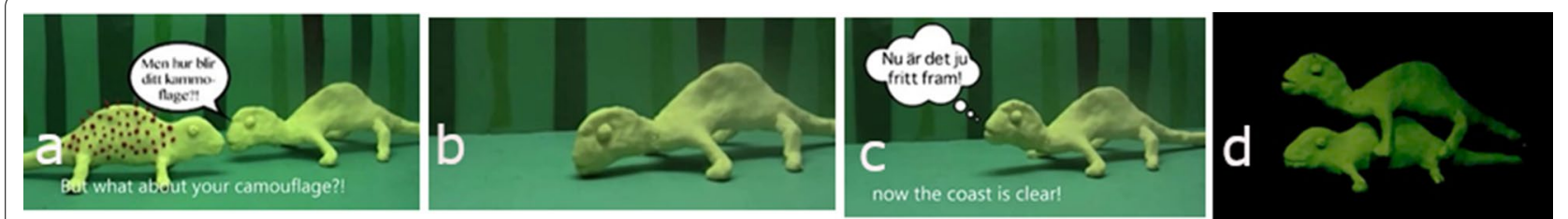

Fig. 11 Due to poor camouflage (a) the lizard's spotty friend is eaten, and after a brief moment of grief (b) the survivor realizes that competition for mates has vanished (c). In the dusk, we note a representation of reproduction, including alluring music in the background (d)

the animations where the animation in Fig. 11 provides a good example. In this regard, one either has good camouflage, or not, and in the latter case, one gets eaten. The one survivor in this animation wins a jackpot of opportunities to mate and reproduce (Fig. 8).

\section{Connections between organizational levels and time}

By connection between different organizational levels, we mean that students are able to link genetic variation to individual variation and/or individual variation to population level. This could have been done with text or through a cut or change of scene in the animation. Only one animation includes the genetic level (Fig. 4) shown both visually and by narration, while nine depict individual and population level (e g., Fig. 2).

Most substantial changes in the traits within populations take a long time and involve many generations (although some traits may become fixed in a single generation under intense selection pressure). The idea of time or generations passing, was indicated in six (33\%) of the animations (Fig. 12a). For example, time was indicated, for example, by mating in one to three generations, or by text ("many generations later"), or alternatively by showing the sun or moon rising and setting, or the earth spinning (Table 4).

\section{How do the conceptions expressed in the stop-motion animations relate to written explanations of evolutionary change and previous research literature?}

To investigate whether our student group was comparable to the students in the research literature we also asked participants to write a response to a test item. The written responses were analysed in relation to key -concepts, and alternative concepts (Fig. 12). The results indicate that the answers given by this student group resemble the results reported in previous research (Andrews et al. 


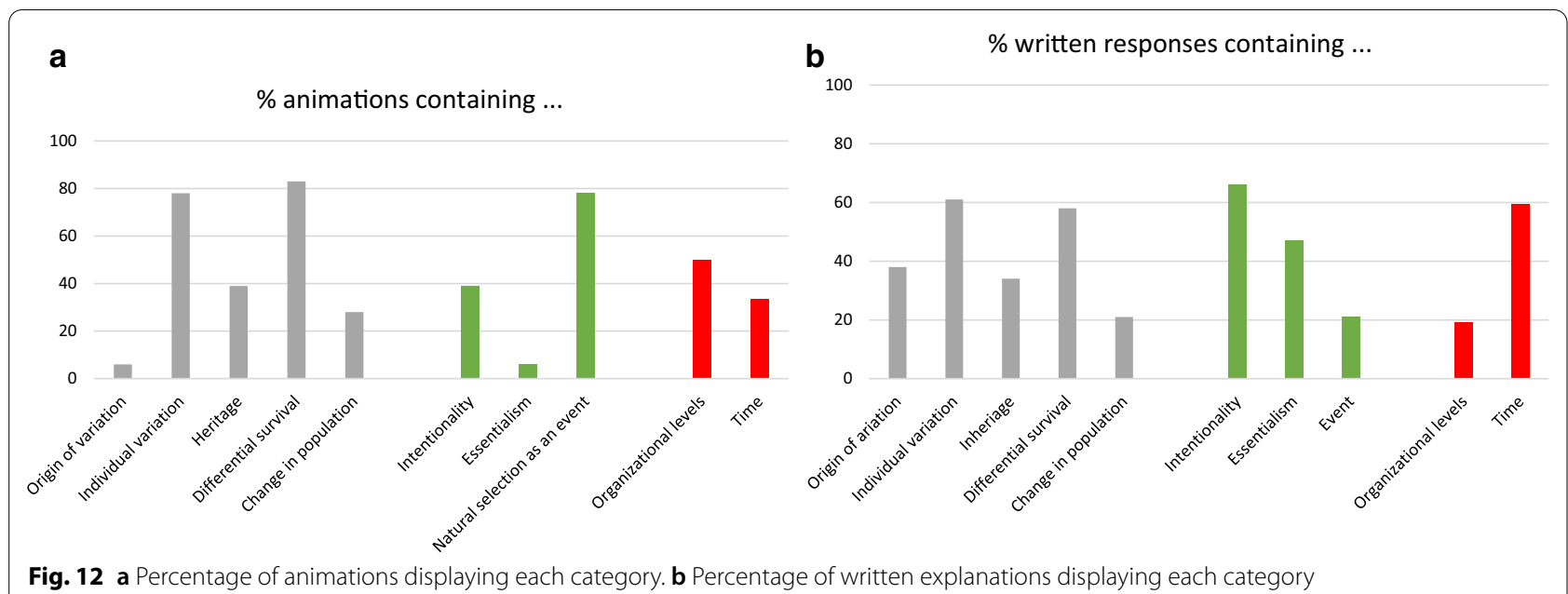

Table 4 Different types of representations of time in the animations

\begin{tabular}{ll}
\hline Illustration of "Time" & $\begin{array}{l}\text { No. of } \\
\text { animations }\end{array}$ \\
Darkening & $6^{\text {a }}$ \\
Generation shifts & 1 \\
Spinning earth & 6 \\
Moon sets & 1 \\
Text & 1 \\
Fast forward & 4 \\
\hline
\end{tabular}

a Sometimes there is more than one indication of time in the stop-motion animation

2011; Göransson et al. 2020) (Fig. 12a, b). In addition, we also analysed the connections between organizational levels (T1) and the explicit compression or expansion of time (T2).

In the corresponding analysis of the animations, we could see both similarities and differences between the results from the animations and the results in the literature.

With the exception of the origin of variation, the occurrence of key -concepts was very similar in the students stop-motion animations as well as in their written explanations (Andrews et al. 2011; Göransson et al. 2020). However, the origin of variation was mentioned more often in the written responses. Eighteen of the students $(38 \%)$ mentioned DNA, genes, or mutation in their written responses but only five (11\%) did so in an appropriate and correct context. As mentioned previously only one animation indicated the origin of variation.

The most salient result was found regarding the alternative conceptions. Intentionality was somewhat less common in the stop-motion animations, and essentialism was shown in only one of them. On the other hand, natural selection represented as a single event was almost four time as common in the animations as in the written responses.

Connections between organizational levels are similar $(20-30 \%)$ in the animations and the written responses, while the connection between different temporal aspects of the process was about twice as common in the written responses $(60 \%)$ than in the animations (33\%).

\section{Discussion}

The theory of natural selection is challenging for learners, and associated potential alternative conceptions are shown to be difficult to change (Chi 2005; Coley and Tanner 2015). However, previous findings indicate that certain changes, such as reformulating a test item, may induce students to focus on different key concepts in their answers (Göransson et al. 2020; Nehm and Ha 2011). Furthermore, results from text-based and spoken language-based tests indicate that changes in the formulation of test items can alter the propensity of many students' to agree with teleological, anthropomorphic, and/or essentialist statements (Gouvea and Simon 2018). Our study explored this issue from a different angle, by investigating how changing the test medium (from pen and paper to the creation of stopmotion animations in this case) influences what students express. Our results show that (with our setting, context, participants, and format), the differences were mainly connected to the alternative concepts.

\section{What means of expression do students use when they are asked to express their knowledge in student-generated stop-motion animations?}

Most of the students appreciated the experience and saw the production of a stop-motion animation as a rare 
opportunity to use their creativity in biology education (Bruna 2013). One effect of the intended audience being peers in a parallel class may possibly have been that the students rather reinforced the entertainment value of their animations, in some cases at the expense of providing a clear explanation for evolutionary change (Nielsen et al. 2020). For instance, music and sound effects seemed to be important to the students, as almost all animations included components of these, but they appeared in many cases to be there purely for aesthetic reasons rather than contributing to the explanatory value. In many cases ideas were adopted from popular culture, such as the march towards man trope, or the Pokémon games. Several groups attempted to twist the narratives from classical ones, such as the story about an animal climbing out of the ocean and starting to walk on land, which was turned around into the story of a land animal that started swimming in the ocean and developed flippers instead of legs. Other groups aligned with examples from the biology textbook, such as showing how giraffes evolved long necks. The animations also provided opportunities for humorous expressions and for exploring odd ideas, as is the case in a bird feeding by falling and striking its prey on the "head". The predators were often depicted as horrible and scary, and a predator attack was dramatized with visualized attempts by the prey to escape. Overall, $89 \%$ of the animations contained some humorous detail, and often towards the end of the animation sequence.

\section{The use of animals in the stop-motion animations}

The students clearly possessed ideas about the concepts of natural selection, and when they were given the opportunity to use their creativity in stop-motion animations we observed great diversity in their expressions. Identifiable animals such as dogs, humans, fish, and turtles were used in most of the animations. Four groups used a more schematic simplified "animal", which might indicate higher representational competence (Ainsworth et al. 2011), through the use of a simple model to explain a principle rather than a concrete realistic example. Another possibility is that using simplified "animals" reflects low self-confidence in making figures with clay. Either way, the more schematic organisms generally allowed the students to work with somewhat larger populations.

We did not instruct the students about what kind of organisms they should use in the stop-motion animations. Nevertheless, in one way the animations all illustrated ENS with animal examples. We suspect that in the minds of the students who produced these animations, evolutionary change is more strongly connected with animals than plants, and/or it is more fun to make an animation with something that moves around a bit. This might be explained by the fact that animals are usually used in education to illustrate evolution. However, if learners ignore the important ecological role of $80 \%$ of the biomass on Earth, this suggests that plants need to be given a greater role in biology education at all levels (Jose et al. 2019). Additionally, it suggests that students might not understand that natural selection is an all-encompassing model of the evolution of life. In fact, there is a need to expose learners to ENS in contexts other than animals (Pugh et al. 2014). For example, Göransson et al. (2020) show that adopting a bacteria context, allowed students to focus on the origin of variation and the micro-levels of organisation. To quote Nehm et al. (2012), "Lessons about natural selection must not solely use examples of trait gains in familiar organisms, but must also discuss cases of unfamiliar animals and plants, trait loss, etc."

\section{What key-concepts are students able to represent in stop-motion animations}

We observed that Individual variation and Differential survival were the most common key-concepts to be represented in the stop-motion animations (as in the written responses). Inheritance and Change in population were somewhat less frequently present in the animations. Origin of variation appears to be the least frequently observed. A possible explanation for the lower expression of the "inheritance", "origin of variation" and "change in population" concepts, might be that these three aspects of natural selection are more abstract, theoretical (Nieswandt and Bellomo 2009) and less relatable than "individual variation" or "different survival".

\section{How do the conceptions, expressed in the stop-motion animations, relate to written explanations in previous research literature?}

The student generated animations did not add any substantial information about the students' knowledge of the tested key-concepts. However, they might tell us something more about students' understanding (Nielsen et al. 2020).

Many studies have found that students tend to use explanations based on intentions. For example, that changes occur in direct response to a new selective pressure or need (Ware and Gelman 2014) or that changes are induced by the environment or the "feelings" or"will" of the species (Harms and Reiss 2019). These investigations have been exclusively based on responses to written items. Our results indicate that representations of the alternative concepts in collaboratively generated student stop-motion animations differ from what has been observed in individually written responses (Fig. 12a, b).

Students expressed essentialist ideas relatively frequently in their written explanations of natural selection, 
but rarely in the animations. Furthermore, we found that ideas about intentionality were expressed less often in the stop-motion animations than in the written responses (Fig. 12a, b). Examples of written responses are presented in Additional file 1: Appendix S1. The lower prevalence of intentionality in the animations may be an effect of the medium. However, another potentially important factor is that the depictive representation of an animation can be more analogous to the represented process (Schnotz 2002), instead of depending on the abstract medium of words. For example, in an animation a population of eight individuals is always present while in text the formulation "the cheetahs had to be fast" leaves more interpretation to the reader.

In addition, many students might lack adequate scientific language, and their explanation of concepts and processes might in some cases have been alternative explanations that did not reflect the students' actual conception. Words such as "adaptation" and "selection" appear both in everyday language (in Swedish) and in biology (Bishop and Anderson 1990), but with different meanings. Such ambiguity may create additional demands when trying to learn a new and abstract concept like natural selection (Rector et al. 2013).

The fact that both variation and essentialism were shown to occur in the same written explanation could be indicative that essentialism was often used metaphorically in the written explanations. We also observed this dual representation when considering the animation displaying essentialism. In the first part of the animation, a population of three individuals with different neck length enter, (individual variation). After a short time, the individual with the shortest neck starve to death because it cannot graze from the tall trees. The two remaining giraffes then continue to evolve longer and longer necks (by showing the selection process once and then speeding up and only showing the evolution).

We suggest that in many cases the descriptive representational mode of writing is ill-suited to representing the complex processes of natural selection and changes in populations. These limitations lead students to use formulations that are not consistent with strict scientific formulations. This finding might be very important and could support further research on the use of alternative methods, such as student-generated stop-motion animations, for helping students to express their knowledge about complex biological processes spanning several organisational levels or magnitudes of time.

Furthermore, stop-motion animations appear to invite students to describe natural selection as an Event (A3). Almost two-thirds of the stop-motion animations indicated that the selection process was an event (occurring during one or very few generations) (Fig. 12a). However, we are not aware of the students' intentions in these scenarios. As in the case of creating large populations, it requires less effort to produce models of a few generations than a thousand. Our observations lead us to argue that in many cases this should not to be seen as a reflection of students' conceptions but rather as an effect of constraints associated with the method of generating the representations (Prain and Tytler 2012). The time-consuming technique forced the students to compromise with time. This conclusion is in fact supported by results from another study that included some of the same animations (Orraryd 2013) where the discussions in the groups working with the stop-motion animations were analysed. Compressions of time and populations are easy in verbal communication but becomes more challenging in a dynamic visual mode, partly because most students are not used to representing ideas in that particular medium (Farrokhnia et al. 2020). This impression is reinforced by the fact that only four groups created a population containing more than four individuals. These students might not have had enough time to produce many individuals if they chose to make realistic animals. This assumption is also supported by the fact that the four groups who created a sizable population used simplified models (e.g., Figs. 2 left panel, $3,4)$.

\section{Character of alternative conceptions}

Regardless of the causes behind the different patterns in the expression of the alternative conceptions, our results are difficult to explain based on the idea of conceptual frameworks, as suggested for instance by Coley and Tanner (2015). Together with other studies which have indicated that both the context, and specific tasks affect what conceptions students reveal (Göransson et al. 2020; Nehm et al. 2012), the results of this study support the hypothesis that so-called alternative conceptions stem to a high degree from students' contextspecific interpretations of each task rather than from cognitive frameworks (Gouvea and Simon 2018). Students, who lack a particular set of concepts, might try to fuse ideas together using the available representational tools (Prain and Tytler 2012) in each situation. Our results shows that the medium and format affect what conceptions are expressed. In conjunction with the finding that many of the written answers could be categorized as both scientific and alternative concepts, we are inclined to support the proposition made by Gouvea and Simon (2018) that response patterns are 
easier to explain with a dynamic model of cognition. However, this proposal needs to be tested further.

\section{Linking different organizational levels}

Only one stop-motion animation managed to link origin of variation to individual variation. However, this link was also seldomly represented in the written explanations. The reason for this could be that the origin of individual variation was not something the students thought of when they were planning the animations (Klymkowsky et al. 2010). If so, this finding verifies the notion that student might not have grasped the process in its entirety. Connecting invisible levels to the visible is difficult (e.g., Tsui and Treagust 2013). Another reason may have been that the students were not able to figure out how to visually show this. In addition, research has shown that neither animations nor videos intended for teaching show this connection very often (Bohlin et al. 2017).

The connection between individual change and changes in a population was shown somewhat more frequently (in four of the 18 animations). It is simpler to generate several animals than to connect them to change in their genes. On the other hand, the time limitation of the session might explain the low number of connections between individuals and population.

Written responses appear to be superior to stopmotion animations as a way for students to express their understanding of the connections between organizational levels or time frames. In the written responses, more than half of the students' mentioned the time dimension of evolution, and time was often quantified by using phrases such as "after a lot of generations" or "after thousands of years" the cheetahs had developed their running capacity. In the animations the time dimension was less commonly illustrated, and it appeared to be difficult, in particular, to show just how much time evolution through natural selection takes. In fact, this reinforces the conclusion that, even though only a few of the stopmotion animations show time, more than half of the students mention time in their written responses. However, students who aimed to show time often used creative solutions to invent some symbolic representation of time. Table 4 shows that students integrate different resources for handling the dimensions of time to the classroom. In a few of the animations, a narrator, (and to a lesser extent text or arrows) provides an explanation stating that "time is passing", or "mutations are happening", for example. Thus, both animation and sound or written texts contribute to communicating these concepts which strengthens the argument that multimedia representations can help students to express their conceptions.

If methods for eliciting the need to express non-perceptual space and time had been included in the teaching sequence (McLure et al. 2020), then perhaps the relationships between the levels of organisation and the magnitudes of time would have been emphasised to a greater extent in the animations.

\section{Limitations of the study}

Since there were 18 animations and 45 written responses, we were not able to compare them directly. The different numbers arose because two or three students worked together on each stop-motion animation, but then each provided their own written response. In the group-work they shared ideas, but the written responses were generated individually. One could of course look at the written responses between groups or select one person from each group and compare their written response and compare it to their video. However, our choice was different. We analysed the 45 student responses and compared the results with the distribution between key concepts and misconceptions in previous research (Andrews et al. 2011; Göransson et al. 2020; Nehm and Reilly 2007). The responses in these studies and our students' responses showed very similar patterns. Thus, we felt that our students could be regarded as very similar to the broader student populations.

\section{Conclusions}

Our study highlights some of the benefits and limitations of using collaboratively generated stop-motion animations and open written response tests to probe students' understanding of evolution through natural selection.

In comparison to written responses collaboratively produces student-generated stop-motion animations did:

- ...effectively have the same pattern of key-concepts, except for origin of variation.

- ...more commonly express natural selection described as an event.

- ...less frequently show essentialism.

- ...increase creativity, humour, and engagement.

- ...encourage students to use different modalities to illustrate time.

However, they did not...

- ...help students to connect organizational levels.

- ...help students to quantify the time dimensions of the process.

Creating stop-motion animations is a time-consuming technique, and this meant that the students tended to take shortcuts and accelerate their storytelling in at least the following three ways. 
- They did not create displays of large populations. Instead, most of them represented variation in only a few individuals.

- They did not produce nice displays of gradual change in populations, but rather only a few individuals, and in most cases only one individual, had a changed trait.

- The numbers of generations/amount of time required for change in the populations was very rarely shown. Instead, changes in the represented populations usually occurred in a rapid, event-like manner.

\section{Implications for teaching}

We suggest that complementing standard paper-and-pen tests with forms of assessment that encompass multiple media such as stop-motion animations can provide a broader view of students' learning progression, thereby possibly increasing teachers' ability to orchestrate the activities (Smith and Tanner 2010). This notion supports claims by Mintzes et al. (2001) that more diverse assessment methods are beneficial for biology education. In addition, it would provide an opportunity to assess other educational goals, such as cooperation, communication and digital competence (Nielsen et al. 2020). Ideally, complements should offer opportunities to use a learning activity for classroom assessment, with an emphasis on avoiding the separation of learning and assessment (Lowe et al. 2017). Moreover, truly creative assignments, such as the generation of animations, clearly offer opportunities to see how aesthetically and entertainingly students can express their knowledge to engage their fellow students.

\section{Implications for the development of collaborative stop-motion animation tasks}

To improve teaching sequences that include student-generated stop-motion animations, we intend to make the following improvements:

1. To make students think about organisms other than animals we aim to limit their freedom of choice of organism and describe the evolutionary change they are to represent. Thus, we will be able to determine students' ability to transfer their knowledge to other organisms and contexts.

2. Allocate more time for the students to write a storyboard. After feedback on the storyboards the students might be inspired to expand their ambitions and could be guided in how to show aspects such as time passing (generations) and how to connect organizational levels.

3. Interview the students after the teaching session to gain information about how the intervention was experienced, and what advantages and difficulties were perceived as associated with the task.

\section{Supplementary Information}

The online version contains supplementary material available at https://doi. org/10.1186/s12052-021-00153-z.

Additional file 1: Appendix S1. Examples of written statements and animations to illustrate each category.

\section{Acknowledgements}

We are grateful to all the students who participated in the study, to Christian Tidebrink and Måns Ahlin for technical support and our colleagues in the EvoVis research group. We are also thankful for the economic support from the Swedish Research Council (Vetenskapsrådet) [Grant Number 2012-5344] (EvoVis) and Linköping University. We are also very grateful for valuable suggestions for improving the manuscript from Dr. Jesper Haglund. Thanks to Dr. John Blackwell for language review. Finally, we thank Professor Konrad Schönborn for the final language check.

\section{Authors' contributions}

DO and LAET designed the study. DO performed the data collection. DO and LAET conducted the data analysis. DO completed the original draft of the manuscript. LAET and DO revised the original manuscript iteratively. Both authors read and approved the final manuscript.

\section{Funding}

The research was partly funded by the Swedish Research Council (Vetenskapsrådet) [Grant Number 2012-5344] (EvoVis) and Linköping University.

\section{Availability of data and materials}

The animations are available from the corresponding author on request.

\section{Declarations}

\section{Ethics approval and consent to participate}

All participants signed a consent form. Since all students were participating as part of their normal school day no approval from an ethics committee was required to conduct this study.

\section{Competing interests}

The authors declare that they have no competing interests.

\section{Author details}

${ }^{1}$ Department of Behavioural Sciences and Learning, Technology and Science Education Research, Linköping University, Norrköping, Sweden. ${ }^{2}$ Department of Science and Technology (ITN) Media and Information Technology (MIT), Linköping University, Norrköping, Sweden.

Received: 16 February 2021 Accepted: 9 August 2021

Published online: 27 September 2021

\section{References}

Abrams E, Southerland S. The how's and why's of biological change: how learners neglect physical mechanisms in their search for meaning. Int J Sci Ed. 2001;23(12):1271-81.

Ainsworth S, Prain V, Tytler R. Drawing to learn in science. Science. 2011;333(6046):1096-7.

Akaygun $\mathrm{S}$. Is the oxygen atom static or dynamic? The effect of generating animations on students' mental models of atomic structure. Chem Educ Res Pract. 2016;17(4):788-807.

Amundsen C, Weston C, McAlpine L. Concept mapping to support university academics' analysis of course content. Stud High Educ. 2008;33(6):633-52. 
Anderson DL, Fisher KM, Norman GJ. Development and evaluation of the conceptual inventory of natural selection. J Res Sci Teach. 2002:39(10):952-78

Andrews TM, Leonard MJ, Colgrove CA, Kalinowski ST. Active learning not associated with student learning in a random sample of college biology courses. CBE Life Sci Educ. 2011;10(4):394-405

Archibald JD. Aristotele's ladder, Darwin's tree: the evolution of visual metaphors for biological order. New York: Colombia University Press; 2014.

Berg A, Orraryd D, Pettersson AJ, Hultén M. Representational challenges in animated chemistry: self-generated animations as a means to encourage students' reflections on sub-micro processes in laboratory exercises. Chem Educ Res Pract. 2019;20(4):710-37.

Bishop BA, Anderson CW. Student conceptions of natural selection and its role in evolution. J Res Sci Teach. 1990:27(5):415-27.

Bohlin G, Göransson A, Höst GE, Tibell LA. A conceptual characterization of online videos explaining natural selection. Sci Educ (dordr). 2017;26(7-9):975-99.

Bruna C. Motivating active learning of biochemistry through artistic representation of scientific concepts. J Biol Educ. 2013;47(1):46-51.

Catley K, Novick L, Shade C. Interpreting evolutionary diagrams: when topology and process conflict. J Res Sci Teach. 2010;47(7):861-82.

Chi MT. Commonsense conceptions of emergent processes: why some misconceptions are robust. J Learn Sci. 2005;14(2):161-99.

Coley JD, Tanner K. Relations between intuitive biological thinking and biological misconceptions in biology majors and nonmajors. Cbelife Sci Educ. 2015;14(1):ar8.

Deaton CC, Deaton BE, Ivankovic D, Norris FA. Creating stop-motion videos with iPads to support students' understanding of cell processes: 'Because You Have to Know What You're Talking about to Be Able to Do It". J Digit Learn Teach Educ. 2013;30(2):67-73.

diSessa A. Toward an epistemology of physics. Cogn Instr. 1993;10(2-3):105-225.

Farrokhnia M, Meulenbroeks RF, van Joolingen WR. Student-generated stopmotion animation in science classes: a systematic literature review. J Sci Educ Technol. 2020;29:797-812.

Ferrari M, Chi MT. The nature of naive explanations of natural selection. Int J Sci Educ. 1998;20(10):1231-56.

Gelman SA, Rhodes M. "Two-thousand years of stasis": how psychological essentialism impedes evolutionary understanding. In: Rosengren KS, Brem SK, Evans EM, Sinatra GM, editors. Evolution challenges: integrating research and practice in teaching and learning about evolution. Oxford: University Press; 2012. p. 200-7.

Göransson A, Orraryd D, Fiedler D, Tibell LAE. Conceptual characterization of threshold concepts in student explanations of evolution by natural selection and effects of item context. CBE Life Sci Educ. 2020;19(1):ar1.

Gouvea JS, Simon MR. Challenging cognitive construals: a dynamic alternative to stable misconceptions. CBE Life Sci Educ. 2018;17(2):34

Graneheim UH, Lundman B. Qualitative content analysis in nursing research: concepts, procedures and measures to achieve trustworthiness. Nurse Educ Today. 2004;24(2):105-12.

Gregory TR. Understanding evolutionary trees. Evol Educ Outreach. 2008;1(2):121-37.

Gregory TR. Understanding natural selection: essential concepts and common misconceptions. Evol Educ Outreach. 2009;2(2):156-75.

Harms U, Reiss MJ. The present status of evolution education. In: Reiss MJ, Harms U, editors. Evolution education re-considered. Cambridge: Springer; 2019. p. 1-19.

Hoban G, Nielsen W. The 5 Rs: a new teaching approach to encourage slowmations (studentgenerated animations) of science concepts. Teach Sci. 2010;56(3):33-8.

Jose SB, Wu CH, Kamoun S. Overcoming plant blindness in science, education, and society. Plants People Planet. 2019;1(3):169-72

Kamp BL, Deaton CC. Move, stop, learn: illustrating mitosis through stopmotion animation. Sci Act. 2013:50(4):146-53.

Kampourakis K. Teleology in biology, chemistry and physics education: what primary teachers should know. Rev Sci Math ICT Educ. 2007:1(2):81-96.

Kampourakis K. Students'"teleological misconceptions" in evolution education: why the underlying design stance, not teleology per se, is the problem. Evol Educ Outreach. 2020;13(1):1-12

Karakoyun F, Yapici IÜ. Use of slowmation in biology teaching. Int Educ Stud. 2018;11(10):16-27. https://doi.org/10.5539/ies.v11n10p16.
Klymkowsky MW, Underwood SM, Garvin-Doxas RK. Biological concepts instrument (BCI): a diagnostic tool for revealing student thinking. 2010. arXiv preprint arXiv:1012.4501. [q-bio.OT]

Lawrence $E$, editor. Henderson's dictionary of biology. London: Pearson education; 2005.

Lowe RK, Boucheix J-M, Fillisch B. Demonstration tasks for assessment. In: Lowe R, Ploetzner R, editors. Learning from dynamic visualization: innovations in research and application. Chambridge: Springer International Publishing; 2017. p. 177-201.

Matuk C, Uttal D. Narrative spaces in the representation and understanding of evolution. In: Rosengren KS, Brem SK, Evans EM, Sinatra GM, editors. Evolution challenges: integrating research and practice in teaching and learning about evolution. Oxford: University Press; 2012. p. 119-44.

Mayr E. The growth of biological thought: diversity, evolution, and inheritance. Cambridge: Belknap P. of Harvard U.P; 1982.

Mayring P. Qualitative content analysis — research instrument or mode of interpretation. In: The role of the researcher in qualitative psychology, vol. 2. 2002; pp. 139-48.

McLure F, Won M, Treagust D. Students' understanding of the emergent processes of natural selection: the need for ontological conceptual change. Int J Sci Educ. 2020;42(9):1485-502.

Mills $R$, Tomas L, Lewthwaite B. The impact of student-constructed animation on middle school students' learning about plate tectonics. J Sci Educ Technol. 2019;28(2):165-77.

Mintzes JJ, Wandersee JH, Novak JD. Assessing understanding in biology. J Biol Educ. 2001;35(3):118-24.

Nehm R, Ha M. Item feature effects in evolution assessment. J Res Sci Teach. 2011;48(3):237-56.

Nehm R, Reilly L. Biology majors'knowledge and misconceptions of natural selection. Bioscience. 2007;57(3):263-72.

Nehm R, Schonfeld IS. Measuring knowledge of natural selection: a comparison of the CINS, an open-response instrument, and an oral interview. J Res Sci Teach. 2008:45(10):1131-60.

Nehm R, Beggrow EP, Opfer JE, Ha M. Reasoning about natural selection: diagnosing contextual competency using the ACORNS instrument. Am Biol Teach. 2012;74(2):92-8.

Nielsen W, Georgiou H, Jones P, Turney A. Digital explanation as assessment in university science. Res Sci Educ. 2020;50(6):2391-418.

Nieswandt M, Bellomo K. Written extended-response questions as classroom assessment tools for meaningful understanding of evolutionary theory. J Res Sci Teach. 2009;46(3):333-56.

Orraryd D. Elevers animationer av evolution. In: Jeppsson F, Haglund J, editors. Modeller, analogier och metaforer i naturvetenskapsundervisning. Stockholm: Studentlitteratur; 2013.

Peterson CN, Ngo P. Creating stop-motion animations to learn molecular biology dynamics. J Microbiol Biol Educ. 2015;16(2):280-1.

Phillips LM, Norris SP, Macnab JS. Visualization in mathematics, reading and science education. Dordrecht: Springer; 2010.

Prain $\mathrm{V}$, Tytler $\mathrm{R}$. Learning through constructing representations in science: a framework of representational construction affordances. Int J Sci Educ. 2012;34(17):2751-73.

Pugh KJ, Koskey KL, Linnenbrink-Garcia L. High school biology students' transfer of the concept of natural selection: a mixed-methods approach. J Biol Educ. 2014;48(1):23-33.

Rector M, Nehm R, Pearl D. Learning the language of evolution: lexical ambiguity and word meaning in student explanations. Res Sci Educ. 2013;43(3):1107-33.

Schnotz W. Towards an integrated view of learning from text and visual displays. Educ Psychol Rev. 2002;14(1):101-20.

Smith Jl, Tanner K. The problem of revealing how students think: concept inventories and beyond. CBE Life Sci Educ. 2010;9(1):1-5.

Southerland SA, Abrams E, Cummins CL, Anzelmo J. Understanding students' explanations of biological phenomena: conceptual frameworks or p-prims? Sci Educ. 2001;85(4):328-48.

Stenlund JI, Tibell LAE. Visualizing macroevolutionary timescales: students' comprehension of different temporal representations in an animation. Evol Educ Outreach. 2019;12(1):art8.

Tibell LA, Harms U. Biological principles and threshold concepts for understanding natural selection. Sci Educ (dordr). 2017;26(7-9):953-73.

Treagust DF, Tsui C-Y. Multiple representations in biological education. Dordrecht: Springer; 2013 
Tsui C-Y, Treagust DF. Introduction to multiple representations: their importance in biology and biological education. In: Tsui C-Y, Treagust DF, editors. Multiple representations in biological education. Dordrecht: Springer; 2013. p. 3-18.

Wandersee JH, Schussler EE. Preventing plant blindness. Am Biol Teach. 1999;61(2):82-6.

Ware EA, Gelman SA. You get what you need: an examination of purposebased inheritance reasoning in undergraduates, preschoolers, and biological experts. Cogn Sci. 2014;38(2):197-243.
Zabel J, Gropengiesser H. Learning progress in evolution theory: climbing a ladder or roaming a landscape? J Biol Educ. 2011;45(3):143-9.

\section{Publisher's Note}

Springer Nature remains neutral with regard to jurisdictional claims in published maps and institutional affiliations.
Ready to submit your research? Choose BMC and benefit from:

- fast, convenient online submission

- thorough peer review by experienced researchers in your field

- rapid publication on acceptance

- support for research data, including large and complex data types

- gold Open Access which fosters wider collaboration and increased citations

- maximum visibility for your research: over $100 \mathrm{M}$ website views per year

At BMC, research is always in progress.

Learn more biomedcentral.com/submissions 